\title{
A REALIZAÇÃO DAS MORAS “ESPECIAIS" 'DO JAPONÊS NO DESEMPENHO DE FALANTES BRASILEIROS
}

Elza Taeko Doi

\section{Introdução}

É fato conhecido que o japonês falado pelos estrangeiros apresenta uma característica peculiar na realização das moras nasais, consonantais e longas, consideradas “moras especiais" da língua (Kindaichi, 1967; Han, 1992; Sugito, 1989). Estas moras, também denominadas de não-plenas (Tabata, 1989), porque não apresentam a estrutura $(\mathrm{C}(\mathrm{G})) \mathrm{V}$ das moras plenas são, no entanto, definidas como portadoras da mesma duração das moras plenas.

Este trabalho pretende mostrar, através de dados extraídos do desempenho formal de brasileiros não descendentes de japoneses falando japonês, manifestações de ordem rítmica envolvendo as moras especiais do japonês. A partir do levantamento e da análise desses dados, esperamos obter subsídios para o ensino do japonês oral, no que diz respeito ao seu aspecto rítmico.

Como ponto de partida apresentamos uma breve caracterização do ritmo do português e do japonês com a finalidade de situar o leitor quanto às diferenças entre as línguas sob esse aspecto.

\section{Ritmo do Português}

O português se caracteriza como língua de ritmo acentual que se baseia em ocorrências de sílabas com acentos de intensidade (sílabas proeminentes) intercaladas por sequiência de sílabas não acentuadas. As línguas de ritmo acentual têm as sílabas 
como unidades rítmicas que se organizam em grupos denominados pés, caracterizados por uma sequiência de uma sílaba tônica (proeminente) seguido de uma ou várias sílabas átonas.

Como este tipo de ritmo se caracteriza pela isocronia acentual, as sílabas não acentuadas estão sujeitas a sofrer alterações na sua duração, conforme o número de sílabas presentes no intervalo das sílabas acentuadas. Verificamos, em conseqüência disso, mudanças na qualidade das vogais, e até mesmo na estrutura silábica decorrente da supressão das vogais.
(/)
( $)$
(/)
$(/)$
$(/)$

Ex.: O Portu/guês se caracte/riza como /língua de /ritmo acentu/al.

(Cada espaço delimitado por / / constitui a unidade rítmica pé. As sílabas tônicas estão marcadas pelo acento agudo.)

\section{Ritmo do Japonês}

O japonês, considerado como uma língua de ritmo mora-timed, organiza-se, em termos rítmicos, por meio de grupos compostos de duas moras.

A mora do japonês é tradicionalmente definida como:

$a$. a unidade de ritmo da língua e se caracteriza também como unidade de duração;

$b$. a menor unidade fonológica de que os falantes de japonês têm consciência, e pode ser constituída de $(\mathbf{C}(\mathrm{G})) \mathrm{V}$. de $\mathbf{N}$, de $\mathrm{C}$, ou de $\mathrm{V}$;

c. a unidade correspondente à escrita kana do sistema de escrita do japonês;

$d$. a unidade portadora de um tom (alto ou baixo); e

$e$. a unidade correspondente ao haku (batida) do japonês.

As moras Nasal (N), Consonantal (C) e Longa (Ỵ), consideradas especiais (tokushuu) ou não-plenas, apresentam algumas restrições na sua ocorrência:

$a$. não constituem a mora inicial de uma palavra.

$$
\begin{array}{lll}
\text { Ex.: sa } n \text { [san] } & \text { i t ta [it:a] } & \text { ka ko o [kako:] } \\
\text { CV N̦ } & \text { V C C CV } & \text { CV CV Y }
\end{array}
$$

b. não são portadoras de núcleo de acento. (A unidade moraica, cujo acento possui a marcação indicadora da mudança de tom para o tom baixo a partir da unidade seguinte, constitui o núcleo do acento.) Em japonês, o núcleo do acento é definido com base na última unidade de tom alto dentro de uma palavra.

$$
\begin{aligned}
& \text { Ex.: a n ka ko o ka ko ji te a sa te } \mathrm{i} \Gamma_{\mathrm{s}} \text { sa tu }
\end{aligned}
$$

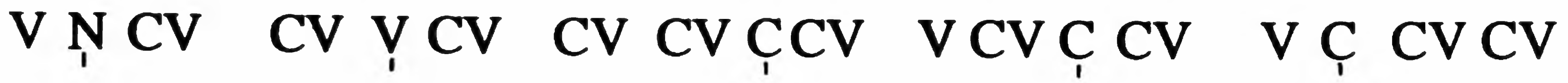


Conforme vimos acima, o acento do japonês é determinado predominantemente pela altura. Possui, além disso, uma função distintiva, como se pode ver pelos exemplos abaixo:

$$
\text { Ex.: } a \text { me "chuva" a } \sqrt{\mathrm{m} e} \text { "bala" }
$$

Cada unidade mora é portadora de um acento alto ou baixo, e a ocorrência do acento se baseia nas seguintes regras:

1. existe apenas uma unidade ou uma seqüência de unidades com acento alto dentro de um item lexical isolado ou de um sintagma. Isto significa que não existem 2 pontos (ou seqüências) altos intercalados por unidade(s) de acento baixo dentro de uma palavra ou sintagma.

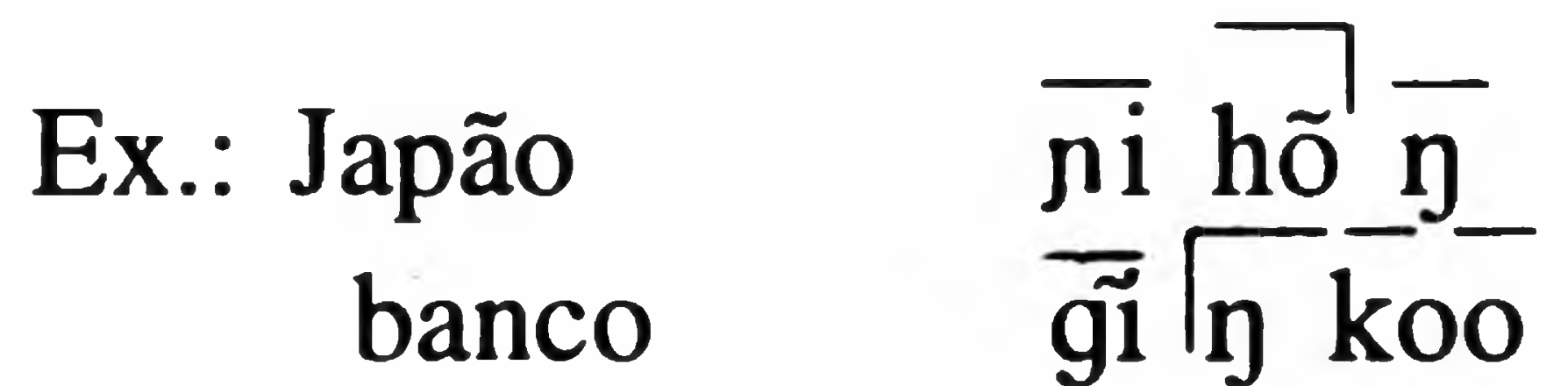

$$
\begin{aligned}
& \text { Banco do Japão } \quad \text { seria: } \quad \overline{\text { ni }} \Gamma_{\text {hõ }} \overline{\mathrm{g}} \overline{\mathrm{ni}} \overline{\mathrm{y}} \overline{\mathrm{k}} \overline{\mathrm{noo}} \\
& \text { e não: } \quad \overline{\text { ni }} \overline{\text { hõ }} \overline{\mathrm{y}} \overline{\mathrm{gi}} \sqrt{\mathfrak{y}} \overline{\text { koo }}
\end{aligned}
$$

2. o núcleo do acento é determinado pela última unidade portadora de acento alto dentro de um item lexical e é marcado por $\neg$ sinal que indica o limite do acento alto. A unidade seguinte $\mathrm{a} \neg$ é portadora de acento baixo.

$$
\text { Ex.: } \overline{\mathrm{a}} \overline{\mathrm{ka}} \frac{\mathrm{t}}{\mathrm{ya}} \frac{\overline{\mathrm{te}}}{\mathrm{mi}} \quad \begin{aligned}
& \text { depois de amanhã } \\
& \text { espelho }
\end{aligned}
$$

3.. no caso do dialeto de Tóquio, considerado a variedade padrão do japonês, acrescenta-se mais uma regra que estabelece a distinção de acento entre a primeira e a segunda unidade de um item lexical. Assim, se a primeira unidade é portadora de um acento alto, a segunda unidade deve obrigatoriamente ser baixa, e vice-versa.

$$
\begin{aligned}
& \text { Ex.: } \overline{\mathrm{ka}} \overline{\mathrm{zo}} \overline{\mathrm{ku}} \quad \text { família } \\
& \overline{\mathrm{tsu}} \overline{\mathrm{ku}} \mathrm{e} \quad \text { escrivaninha }
\end{aligned}
$$

\section{Os Dados}

Os dados utilizados neste trabalho foram coletados por ocasião do Concurso de Oratória realizado em São Paulo pelo Centro de Estudos da Língua Japonesa, nos anos de 1991, 1992 e 1993. Esse evento é realizado anualmente pelo referido Centro, com o patrocínio do Consulado Geral do Japão em São Paulo e da Fundação Japão. Os candidatos são divididos em três grupos $(\mathrm{A}, \mathrm{B}, \mathrm{C})$ conforme o seu nível de proficiência: os candidatos selecionados para o grupo A são os mais proficientes, descendentes 
de japoneses que contam com vários anos de estudo do japonês; os candidatos do grupo B, também descendentes de japoneses, são menos proficientes e participam do concurso pela primeira vez. $\mathrm{O}$ grupo $\mathrm{C}$ é constituído de candidatos não-descendentes de japoneses. O tema a ser apresentado é de livre escolha do candidato.

$\mathrm{O}$ nosso estudo incide sobre as apresentações do grupo $\mathrm{C}$. Embora numa avaliação impressionística, tivéssemos reconhecido também nos candidatos do grupo B as características presentes na fala dos componentes do grupo $\mathrm{C}$, optamos por este último por ser constituído de falantes nativos de português que aprenderam o japonês em contexto formal. As características do desempenho desses falantes poderiam ser consideradas representativas do japonês dos brasileiros e revelar traços decorrentes das diferenças entre o sistema fonológico das duas línguas.

As apresentações foram gravadas em aparelho de áudio SONY Cassette-Corder TCM-11, posteriormente transcritas com o uso de Alfabeto Fonético Internacional, fazendo-se as marcações de duração das unidades moraicas ( $\sim$ longa, $\cap$ média, $\cup$ breve, $\smile$ brevíssima), do acento de intensidade (pelo sinal ' anteposto à unidade acentuada) e de altura (-alto, - baixo). Foram ainda registradas marcações entonacionais sobre as seqüências moraicas $(\frown)$, as pausas $(\wedge)$, conforme a ocorrência delas. Por uma questão metodológica, restringimos nossa observação e análise aos vocábulos compostos de mais de três unidades moraicas para uma melhor apreensão dos traços do japonês.

Exemplos extraídos dos dados:

$\begin{array}{llll}\cup-\cup & \cup \cup \cup \cup \cup \cup- & \text { entonação } \\ \text { ju lme na } \\ \text { famoso }\end{array}$

\section{O Desempenho dos Falantes}

Apresentamos a seguir os tipos de realizações problemáticas atestados no corpus analisado.

\section{Moras Longas}

No que diz respeito às moras longas, foram constatados:

a. casos em que a mora longa simplesmente não é realizada, como por exemplo em:

$\begin{array}{lll}\cup & \cup & \cup \\ x i & \text { ko } & \text { ki }\end{array}$ por

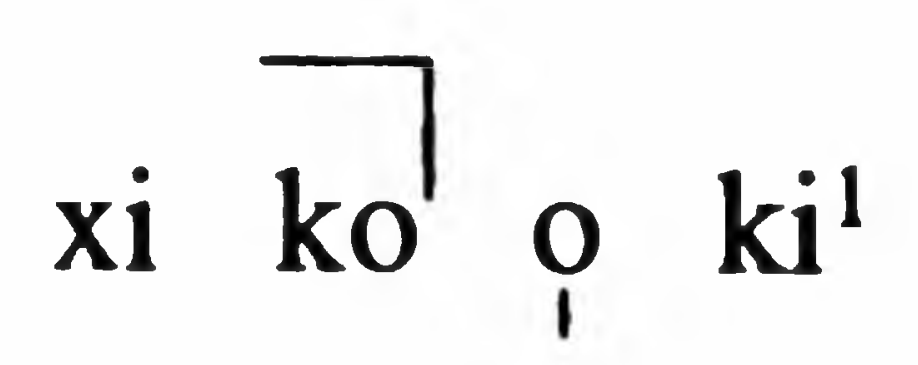

avião

1. Forma correspondente em japonês. 
b. casos em que a mora longa é apagada em decorrência do acento de intensidade que acaba subsumindo a duração da unidade moraica:

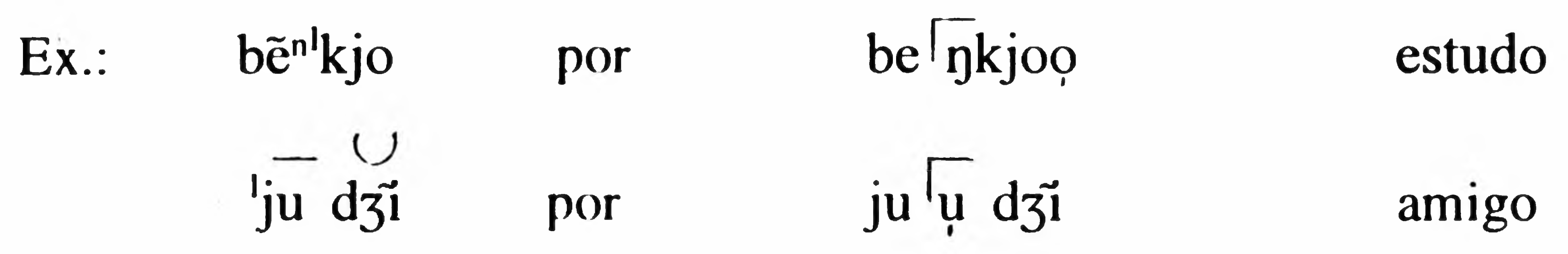

c. casos em que os segmentos que representam as moras longas não são interpretadas como uma unidade independente em termos rítmicos, não ocupando portanto a duração de uma mora. Percebe-se, no entanto, uma tentativa de realizá-la tornando a duração da unidade anterior mais longa. Todavia, este alongamento na duração silábica não representa adequadamente a realização de duas moras porque não corresponde ao resultado de duas unidades moraicas (duas batidas).

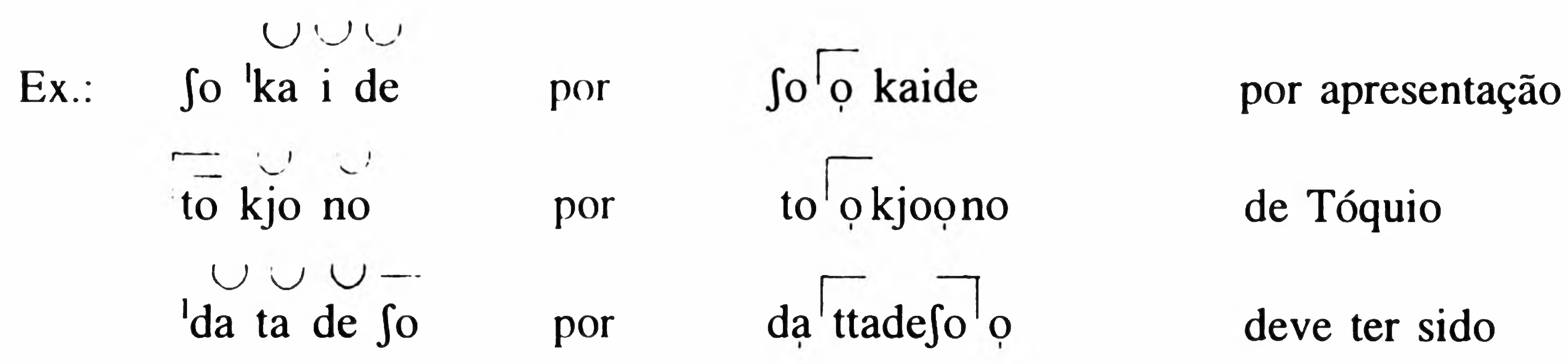

d. casos em que há atuação do acento, mas de modo diferente do que ocorre em $(b)$ acima, como:

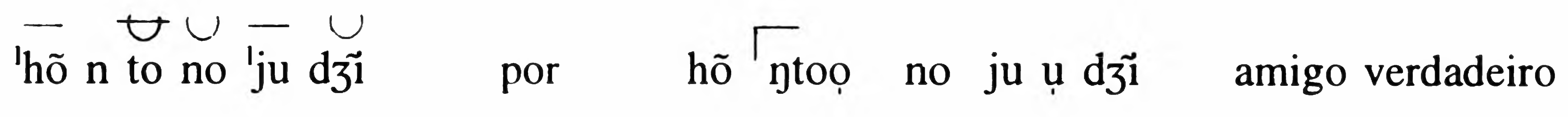
mostra a atuação do acento de intensidade na duração das moras seguintes, tornando-as breves.

e. casos como:

\begin{tabular}{|c|c|c|c|}
\hline $\mathrm{ni}$ ke:d $3^{1^{n}}$ & por & nilkkeẹ dz̃ $\eta$ & descendente de japonês \\
\hline 'su: ka a wa & por & du u kanwa & costume (tópico) \\
\hline subaral $\int \mathrm{i}$ : & por & sumbara $\hat{i}_{i}$ & maravilhoso \\
\hline
\end{tabular}

mostram, por um lado, uma realização adequada em termos de caracterização da mora longa, constituída, como vemos, por duas unidades moraicas. Entretanto, estas realizações apresentam uma peculiaridade entonacional decorrente, a nosso ver, da interpretação que o falante atribui: 1 . às moras longas como partes da mora anterior, 
constituindo, assim, uma unidade correspondente à sílaba longa (representada por CVV): e 2. à representação da duração em conjunto com a marcação acentual baseada na intensidade, recorrendo ao apoio da entonação (entonação ascendente seguida de descendente).

Para preservar a duração da mora longa (interpretada como duas moras), realizada com acento de intensidade, o falante recorre ao apoio da entonação cujo resultado acaba refletindo no contorno entonacional.

\section{Moras Nasais}

Podemos dizer que as moras nasais na fala dos brasileiros tomam as seguintes feições:

a. a mora nasal não é realizada e a unidade moraica que lhe antecede passa a ser nasalizada, muitas vęzes com alteração na qualidade vocálica.

Ex.: hã 'taiji $\quad$ por hã $\Gamma_{n}$ ta $\mathrm{i}$ ni

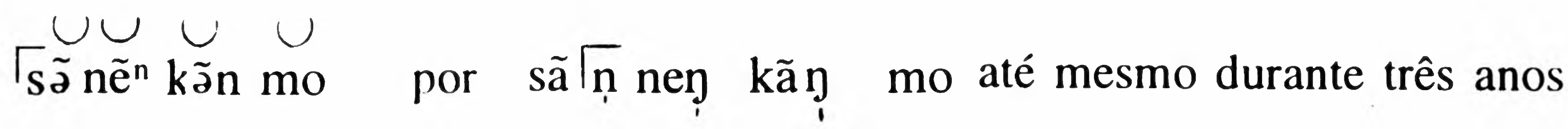

$\mathrm{fu}^{1} \mathrm{dã}$ no $\cup^{\prime} \quad$ por $\Phi u$ dãn no do cotidiano

b. o segmento nasal se faz presente mas como elemento que trava a sílaba anterior (representamos esse segmento em tamanho menor porque, na maioria dos casos, percebia-se a realização desse som como breve).

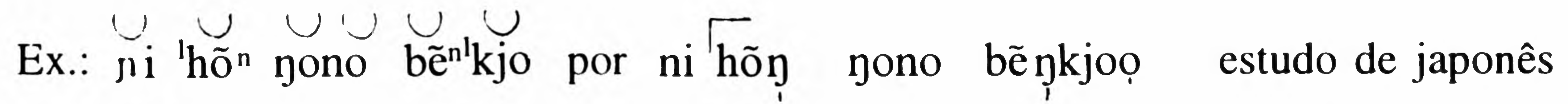

$$
\begin{aligned}
& \text { hã }{ }^{n}{ }^{\prime} \text { tai } \quad \text { por hã } \Gamma_{\text {ngtai }} \text { contrário }
\end{aligned}
$$

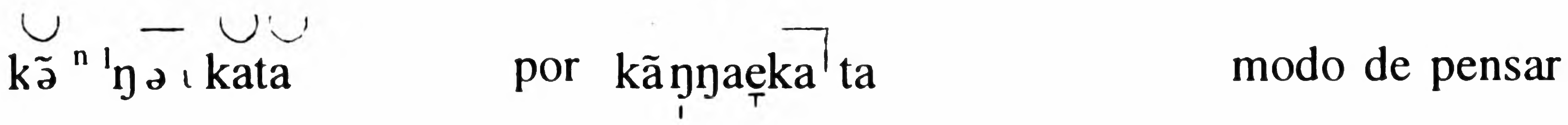

c. em algumas ocasiões, atestam-se casos que, em termos de duração, seriam comparáveis com os de falantes japoneses, mas com resultado fonético distinto. A inadequação fonética seria decorrente tanto do tipo de acento quanto da posição do mesmo.

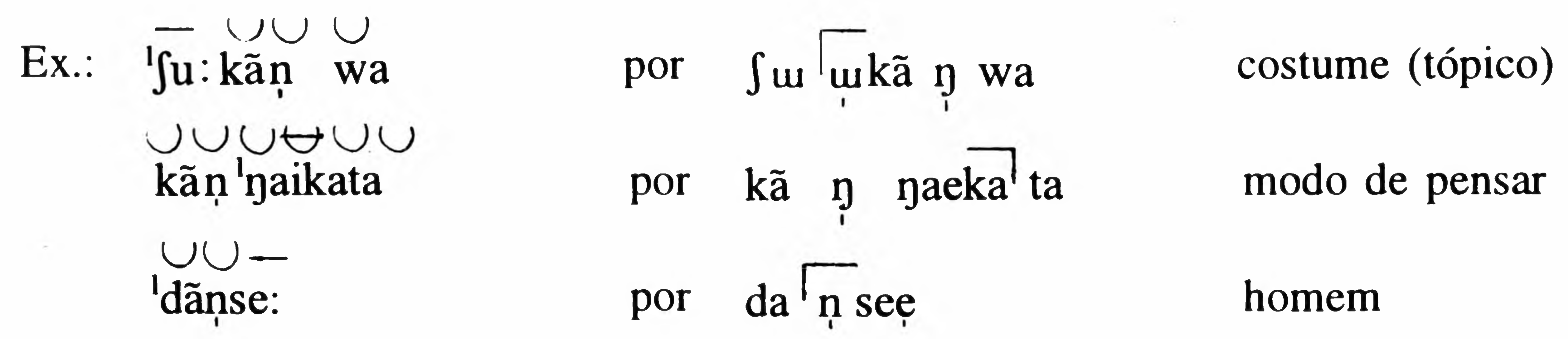




\section{Moras Consonantais}

Em relação às ocorrências da mora consonantal, chegamos às seguintes constatações:

a. predominantemente, a mora consonantal não marca presença na pronúncia dos brasileiros. Somente a marcação acentual é feita na unidade imediatamente posterior ou anterior às moras consonantais.

\begin{tabular}{|c|c|c|c|c|}
\hline \multirow[t]{2}{*}{ Ex.: } & $\begin{array}{c}(u) \\
z^{\prime} \text { tai }\end{array}$ & por & $\mathrm{ze}^{\Gamma} \Gamma_{\text {tai }}$ & absolutamente \\
\hline & ha'kiri & por & ha $\Gamma_{k} k i$ ri & claramente \\
\hline & 'moto & por & $\mathrm{mol}^{\mathrm{l}}$ to & mais \\
\hline
\end{tabular}

Estes dados indicam-nos que, para o falante de português, somente a marcação acentual possui uma realidade fonética e fonológica.

b. ocorrem, no entanto, realizações que refletem uma percepção dessa unidade por parte dos falantes, como por exemplo em:

\begin{tabular}{|c|c|c|}
\hline 'nil põn & por nip põy & Japão \\
\hline 'rip & por ni ṕpõy no & língua japonesa \\
\hline 'to: temo & por toittemo & muito \\
\hline
\end{tabular}

Embora não haja uma atribuição de um estatuto moraico às moras consonantais, a presença da glotal $[\neg$ ] e da bilabial [p] em [hif] e [hip] pode indicar a preocupação do falante em marcar a unidade moraica representada pela mesma consoante da mora seguinte a ela. No caso de ['hip $\wedge$ 'põ go], a presença de uma pausa entre os dois segmentos vem evidenciar a percepção da mora consonantal surda através da interrupção na sequiência da palavra. Já no caso de [ 'to:temo ], verificamos uma tentativa de representar a mora silenciosa [t] através do alongamento da sílaba que antecede a mora consonantal. Trata-se de um recurso muito utilizado entre os alunos que já percebem a existência dessa unidade moraica mas que ainda não a realizam de forma adequada.

\section{Considerações Finais}

Foram raras as realizações adequadas das moras especiais verificadas nos dados. Além disso, a recorrência de casos, indicando uma certa uniformidade no desem- 
penho dos falantes, parece apontar uma dificuldade sistemática dos falantes de português na realização dessas moras.

Dentro da conceituação das moras do japonês como Haku (lit. batidas), o que ocorre nos dados é a ausência da "batida" necessária para representar cada uma dessas moras. As unidades moraicas, representadas pela consoante, pela nasal e pela vogal, passam a ser incorporadas como parte da mora anterior, adquirindo uma estrutura silábica do tipo CVC do português, apagando, com isso, o resultado durativo que a mora ocupa no enunciado.

Através destes dados, podemos também dizer que é grande a influência do ritmo acentual do português tanto na realização quanto na não-realização das moras especiais.

A atuação do acento de intensidade, que tem a propriedade de dar uma unidade às palavras e de ser o elemento determinador do pé rítmico em línguas de ritmo acentual, manifesta-se:

a. na realização das moras nasais e consonantais como partes da sílaba do tipo CVC, e da mora longa como parte da sílaba longa.

\begin{tabular}{|c|c|c|c|}
\hline $\begin{array}{l}\text { hõ }{ }^{n} \text { no } \\
\text { CVC }\end{array}$ & apenas & $\operatorname{lip}_{C V C} \wedge$ pai & cheio \\
\hline N̦ & & C & \\
\hline 'Su: kã ${ }^{n}$ & costume & 'to : kjo: & Tóquic \\
\hline CVV CVC & & CVV CVV & \\
\hline Y $\quad N$ & & $\mathrm{~V}$ & \\
\hline
\end{tabular}

b. na mudança da qualidade vocálica e na diversidade da duração das unidades como em:

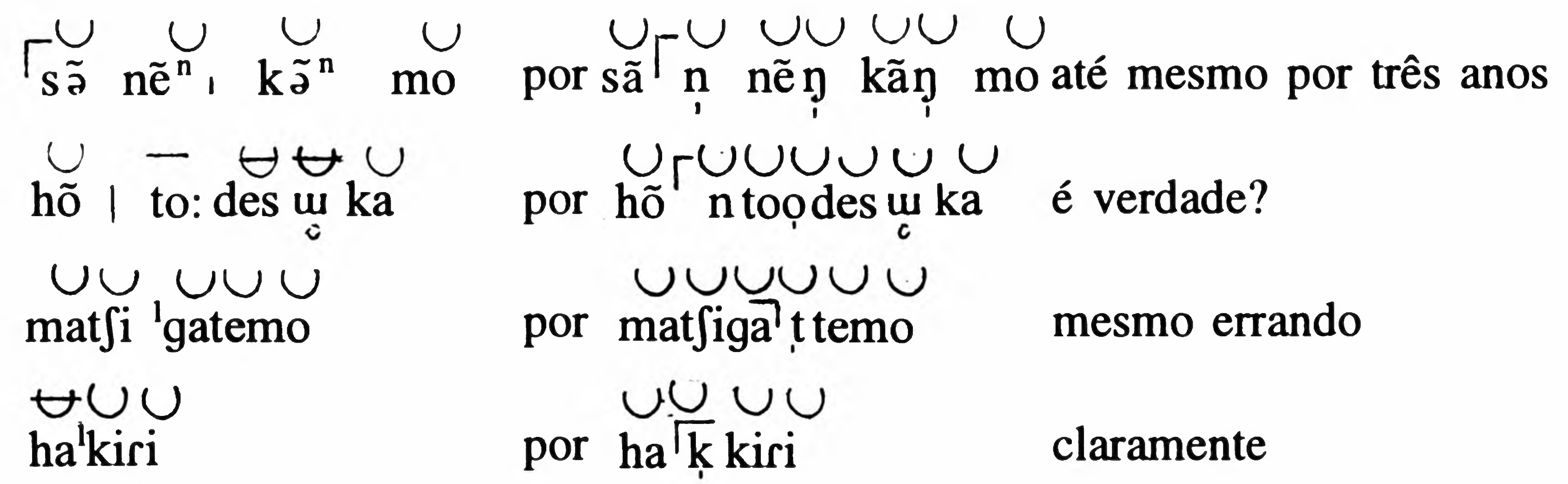

Percebe-se, através dos dados, que as unidades "acentuadas" dos vocábulos do japonês (a última unidade com tom alto da esquerda para a direita) são marcadas com o acento de intensidade, e as sílabas adjacentes a elas (antes e/ou depois da sílaba acentuada) adquirem uma variabilidade na duração, tornando-se brevíssimas. 
A influência do ritmo acentual se torna marcante em unidades frasais maiores como em:

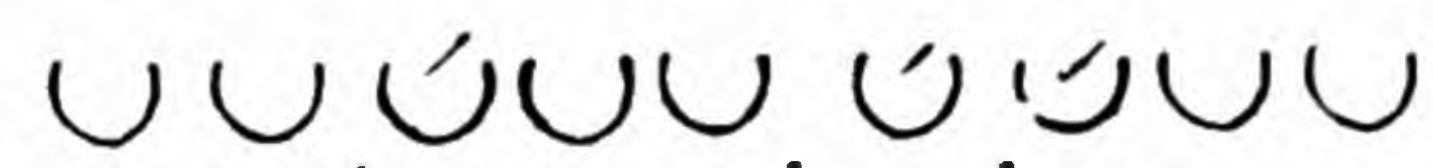

omoi'kite ni'hõ 'e iko

decidi com firmeza que iria ao Japão.

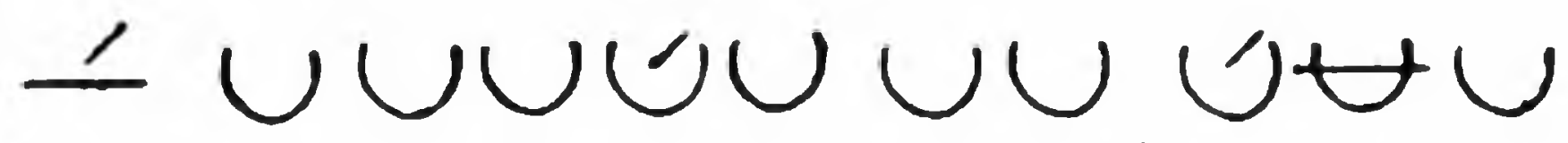

'domo ari'gato gozai'mafi ta

muito obrigado

$\cup-\cup U \forall U \cup U \cup \cup \cup$

ha ${ }^{\text {' }}$ taino koto'ga taku'sã ari'mas

há muitas coisas opostas

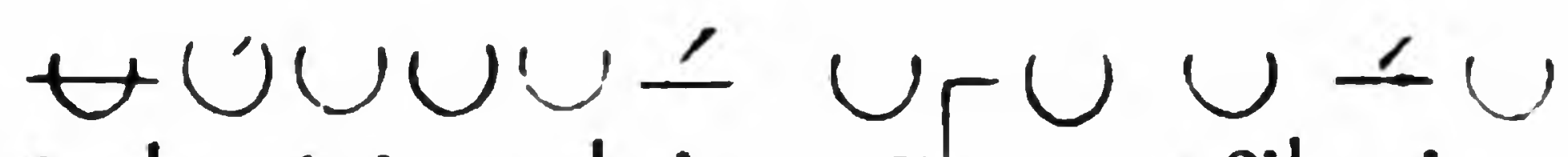

bu'radziruto'nip põ no t toi'gaiga.

a diferença entre o Brasil e o Japão...

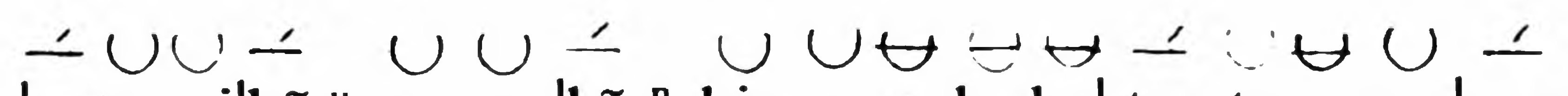

quero continuar

'zuto ni'hõ" no no 'bẽ " kjo o cudzuke' ta । to omo ı'mas

estudando o japonês

onde se percebe o pé rítmico através da ocorrência de sílabas tônicas (marcadas com acento agudo nos exemplos) em intervalos de tempos regulares.

Embora o acento predominante nos dados tenha sido o de intensidade, constatamos uma certa regularidade também quanto à localização dos acentos. As unidades acentuadas no japonês falado pelos brasileiros correspondem mais ou menos àquelas que no japonês são caracterizadas como a segunda unidade moraica das palavras cuja marcação acentual se define apenas pela mudança para o tom alto (marcadas por \lceil nos exemplos).
Ex.: $\quad \mathrm{t}^{\mathrm{i}} \mathrm{i}^{\mathrm{i}} \mathrm{aai}$
por tsi nai
diferença
$\cup \cup \forall \cup$
ka joteta
por ka ${ }_{\text {jot teta }}$
freqüentava

Por outro lado, o desvio na localização do acento (mesmo com o uso de acento adequado, isto é, o acento de altura) ocorre como uma tendência nos casos que envolvem as moras especiais, como por exemplo em:
1. Ju: $\mathrm{Uan}$
por $\quad$ u u kay
costume
2. ni hõ $n$
por nihõ $\rceil_{\mathfrak{l}}$
Japão

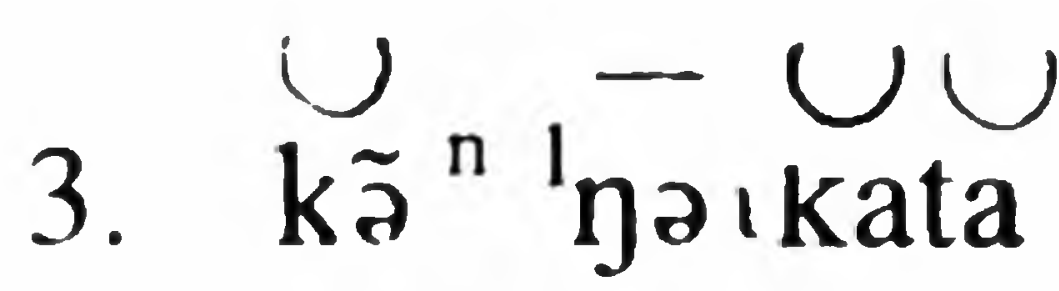
por $\quad k \tilde{a}^{\lceil} \mathfrak{y}$ naeka' ta
modo de pensar
4. $\underset{b \tilde{e}^{n}{ }^{\prime} k j o}{U}$
por be $\Gamma_{\mathfrak{l}}$ kjoọ
estudo
5. $\mathrm{ni}_{\mathrm{ke}}$
por ni $\quad$ k keẹ
descendente de japonês
$\cup_{\text {r. }} \cup U$
6. ja pari
por ja ppa ri
certamente 
onde se percebe a incorporação das moras especiais como partes de uma outra sílaba com deslocamento do acento por anteposição $(1,2)$, por posposição $(3,4)$, ou onde ocorre simplesmente a eliminação das moras especiais $(5,6)$.

O volume 12 da série Japanese for Foreigners - Hatsuon.Chokai (Pronunciation \& Task Listening), diferentemente de outros manuais, apresenta uma abordagem da língua que aparentemente leva em conta o aspecto rítmico do japonês. Essa descrição se baseia na proposição de sílaba longa e sílaba breve conforme o número de moras presentes nas sílabas: a sílaba breve seria constituída de uma mora $(C(G)) V$. e a sílaba longa constituída de uma mora $(\mathrm{C}(\mathrm{G})) \mathrm{V}+$ uma mora especial.

Esta proposta, no entanto, poderia não levar ao resultado esperado com relação à realização das sílabas longas, principalmente pelos aprendizes cuja primeira língua se caracteriza pelo ritmo acentual como é o caso do português. Os alunos realizariam as sílabas longas do japonês como uma sílaba travada do português (C)VC, anulando, com isso, o papel da mora especial dentro da sílaba longa do japonês. Consideramos que a proposta apresentada em Hatsuon.Chokai, que segue a mesma estrutura silábica apresentada em Abe (1987) e Poser (1984), parte de uma perspectiva do analista e não do usuário representado pelos aprendizes da língua. Trata-se de uma organização elegante em que as unidades moras são incorporadas em uma unidade maior, a sílaba, mas com possibilidade de, em termos fonéticos, resultar no apagamento das moras nasais e principalmente das moras consonantais, devido à similaridade que apresenta com a estrutura da sílaba do português.

Para os falantes de português, cuja língua não possui distinção fonológica na duração das unidades silábicas, torna-se difícil a apreensão e a realização do contraste fonológico entre as unidades longa e breve, principalmente quando esse contraste se baseia na atualização de duas moras versus uma mora. $\mathrm{O}$ alongamento da unidade moraica a que o falante recorre, sem marcação de limite articulatório e/ou acentual, seria uma tentativa de interpretar foneticamente a seqüência representada por duas moras.

A isocronia das unidades rítmicas do japonês é assunto amplamente abordado na literatura que trata da fonologia da língua (Jouo, 1977; Kindaichi, 1981; Hattori, 1976; Sugito, 1989). Em manuais de língua japonesa são freqüentes as observações de que as unidades moraicas são realizadas com durações mais ou menos iguais.

Os dados analisados, no entanto, mostraram que a simples referência à duração das moras como tem sido comumente feita nos manuais de ensino não é suficiente para a apreensão das unidades moraicas, principalmente das moras especiais. Isto ocorre sobretudo quando o aprendiz carrega consigo elementos do ritmo acentual como o de português cujo acento exerce uma influência determinante na organização rítmica da língua.

Além disso, consideramos que a caracterização das moras baseada na duração não é adequada porque reflete a observação externa do produto de uma realização, não expondo aos aprendizes as formas de dominar o processo. Se atribuirmos às moras a caracterização de "batidas" ou "marcadores de tempo", evitar-se-iam casos de apagamento das moras especiais porque elas seriam marcadas na seqüência da fala como uma unidade "concreta" (é o caso das moras nasais), ou não atualizadas mas presentes como uma unidade silenciosa no enunciado, como é o caso das moras consonantais e longas. 
Temos consciência de que os dados que utilizamos em nossa análise, resultantes de uma produção trabalhada, isto é, exercitada com antecedência pelos candidatos, provavelmente sob a orientação de professores de japonês, poderiam representar uma limitação na abordagem da questão em estudo. Um desempenho mais natural e espontâneo poderia manifestar uma maior diversidade de casos, o que possibilitaria uma descrição mais abrangente. Contudo, para o objetivo que nos propusemos neste trabalho, de proceder a um levantamento preliminar de casos, podemos dizer que os dados foram adequados, ou até mesmo ideais. De um lado, os informantes são bem representativos, já que como falantes nativos da língua podem revelar interferência do português, e por outro lado, por se tratar de uma fala resultante de muita reflexão, as manifestações problemáticas verificadas refletiriam uma tendência que transparece mesmo em um desempenho controlado ${ }^{2}$.

\section{Bibliografia}

ABE, Y. "Metrical Structure and Compounds in Japanese”, In: Takashi Imai and Mamoru Saito (eds.). Issues in Japanese Linguistics, Dordrecht-Holland/Providence-USA, Foris, 1987.

BekKu, S. Nihongo no Rizumu (O Ritmo do Japonês). Tóquio, Kodansha, 1977.

Jouo, H. “Gendai Nihongo no On-In-” ("Fonologia do Japonês Contemporâneo'). In: On-In- (Fonologia), série Nihongo 5, Tóquio, Iwanami, 1977.

HaN, M. "The Timing Control of Geminate and Single Stop Consonants in Japanese: A Challenge for Nonnative Speakers'. Phonetica, 49: 102-127, 1992.

Handa, T. Imin no Seikatsu no Rekishi (História da Vida dos Imigrantes). São Paulo, Centro de Estudos Nipo-Brasileiros, 1979.

HatTori, S. Gengogaku no Hoho (Métodos em Lingüística). Tóquio, Iwanami, 1976.

KIndAICHI, H. Nihongo On-In- no Kenkyuu (Estudo da Fonologia do Japonês). Tóquio, Chuookooron, 1981.

(org.). Meikai Nihongo Akusento Jiten (Dicionário de Acento do Japonês). Tóquio, Sanseido, 1958.

POSER, W. J. "The Phonetic and Phonology of Tone and Intonation in Japanese" Tese de Doutorado, MIT, 1984.

Sugrto, M. “'Onsetsu ka Haku ka - Cho-on, Hatsu-on, Soku-on” (“Sílaba ou Haku? - Moras Longas, Moras Nasais e Moras Consonantais"). In: M. Sugito (org.). Nihongo no Onsei - On- in- (I) vol. 2, série Nihongo to Nihongokyoiku, Tóquio, Meiji-Shoin, 1989.

Tabata, T. "Nihongo no Onsetsu Koozoo ni tsuite - Shuyoubu to shyushokubu" (ingl., "Syllable Structure in Japanese: Headmodifier Dependencies"), In: Gengo Kenkyuu 95, 144-175, 1989.

"Nihongo no Onsetsu Koozoo to Mota" ("Estrutura da Sílaba do Japonês e Mora”). In: Gaikokugo to Nihongo (Língua Estrangeira e Japonês), série Ooyoo Gengogaku Kooza 2, Tóquio, Meiji-Shoin, 1989.

Nihon Hoso Kyokai (org.). Hatsuon Akusento Jiten (Dicionário de Pronúncia e Acento). Tóquio, NHK, 1994.

2. Agradeço às Professoras Maria Bernadete M. Abaurre, Ester M. Scarpa, Raquel S. Fiad e Vandersi S. Castro pelos comentários sobre o texto. 